\title{
Midterm follow up in patients with reduction ascending aortoplasty
}

\author{
Arndt H Kiessling*, Eva Odwody, Alexandra Miskovic, Ulrich A Stock, Andreas Zierer and Anton Moritz
}

\begin{abstract}
Background: The reduction ascending aortoplasty in patients with an aortic ectasia/dilatation is a common procedure during concomitant cardiac operations. Aim of the follow up study was the evaluation of possible re-dilatation and complications.

Methods: From 1998 to 2010124 patients (69\% male; mean age 66.6 12 ys) with ectasia of the ascending aortic who had no further indication for an aortic replacement, were included. The mean preoperative diameter of the ascending aorta was $4.2 \pm 0.6 \mathrm{~cm}$. The patients risk profile was moderate (mean EF $51 \% \pm 11 \%$, Euroscore $4.2 \pm 2.1$ ). To treat the dilatation of the ascending aorta, a longitudinal incision was performed and a strip of the aortic wall was resected. A reduction aortoplasty was carried out with a double-layered suture line using a 4/0 Prolene mattress suture with an additional 4/0 Prolene running suture. A follow up (rate 95\%) was performed by echocardiography- and clinical examination.

Results: All patients underwent reduction aortoplasty associated with a primary cardiac surgical procedure (AVR 63\%, CABG 13\%, other or combination 24\%). The intrahospital mortality rate was 4\%. Four aortic bleeding complications occurred. After a mean postoperative period of $57 \pm 39$ months, the ascending aortic diameter $(3.6 \pm 0.6 \mathrm{~cm})$ was still significantly $(P<0.01)$ reduced. No postoperative aortic-related complications including aortic rupture, dissection and reoperation were observed. In 4 patients, the ascending aorta had re-dilated to the preoperative diameter.
\end{abstract}

Conclusion: Reduction ascending aortoplasty without external wrapping is a safe procedure with acceptable midterm results in patients with asymptomatic dilatations and concomitant cardiac surgical procedures.

Keywords: Reduction ascending aortoplasty, Aneurysm, Aorta, Follow-up study, Predictor

\section{Background}

A number of surgical techniques and materials are currently available for the treatment of aneurysms of the ascending aorta. Choosing the right technique requires careful review of the various factors, such as morphology of the aneurysm, dilatation of the aortic root, an additional aortic defect and the risks associated with surgery $[1,2]$.

If the dilatation affects only the ascending aorta, aortic replacement is the most common procedure and may potentially be combined with aortic valve replacement. This procedure provides good results [2] but is still associated with significant risks. Perioperative mortality and morbidities can vary up to $10 \%$ [1-4].

\footnotetext{
* Correspondence: cardiac.surgeon@dr-kiessling.com

Department of Thoracic and Cardiovascular Surgery, Johann Wolfgang

Goethe University, Theodor Stern Kai 7, Frankfurt am Main 60590, Germany
}

Reduction ascending aortoplasty (RAA) constitutes an alternative to replacing the ascending aorta in patients with ascending aneurysm without involvement of the aortic root [5]. This is a viable procedure which has demonstrated a number of advantages (less invasive as compared to replacement with a Dacron graft, shorter aortic clamping time, lower risk of bleeding) [6-8]. In addition, lower mortalities and morbidities were reported in patients with RAA [9]. The RAA remains, however, a controversial surgical option due to the potential risk of re-dilatation. This is why the procedure is generally limited to patients with a high perioperative risk. [2]. Reduction ascending aortoplasty is often used in older patients with non-dissecting aortic aneurysm, in particular as an added procedure with concomitant cardiosurgical intervention $[8,9]$.

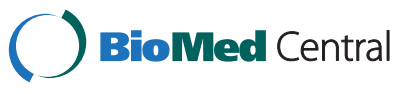


Various techniques of aortoplasty are described in literature. Oftentimes synthetic wrapping is used in addition for external support. Our follow-up study, however, included only patients who underwent surgery with the Robicsek et al technique $[7,10]$ (without external support). This follow-up study was designed to assess medium long-term results of non-Dacron supported RAA procedures and determine the potential predictors for re-dilatation.

\section{Methods}

From January 1998 until 2010, 124 patients underwent reduction ascending aortoplasty associated with dilatation and ectasia of the ascending aorta. From 2011 to 2012 the patients were asked to return for a follow-up echocardiography at the Frankfurt am Main University Hospital. The study had been approved by our institutional ethics committee and the investigator obtained written consent from each patient (decree 184/12 Ethic committee Goethe University, Frankfurt, Germany). The aortoplasty was performed when replacement of the ascending aorta was not indicated for patients $(>5 \mathrm{~cm})$ or existing pre-operative concomitant diseases would have considerably increased the risk associated with surgery.

The clinical variables are listed in Table 1 . The mean age was $66.6 \pm 12$ years (min. 22 years/max. 89 years) $\mathrm{N}=85$ patients were male (69\%) and $92.7 \%$ in the New York Heart Association functional class $>$ II. In order to determine the pre-operative aortic diameter, we performed transthoracic echocardiography or radiological diagnostics (computer tomography). The mean pre-operative aortic diameter measured $4.2 \pm 0.6$ $\mathrm{cm}$ (range 2.8-5.7 cm). None of the patients presented with Marfan syndrome or other genetic disorders for which aortoplasty would be contraindicated. In all patients, the aortic dilatation was limited to the ascending aorta without involvement of the aortic root or aortic arch. The

Table 1 Preoperative parameters

\begin{tabular}{lll}
\hline Items & Number or mean \pm SD & Percent or range \\
\hline Age (years) & $66 \pm 12$ & $22-89$ \\
Male & $\mathrm{N}=85$ & $69 \%$ \\
Body weight $(\mathrm{kg})$ & $76 \pm 15$ & $45-114$ \\
Body height $(\mathrm{cm})$ & $171 \pm 8.5$ & $152-189$ \\
Aortic valve disease & $\mathrm{N}=78$ & $63 \%$ \\
Bicuspid & $\mathrm{N}=39$ & $44 \%$ \\
Coronary heart disease & $\mathrm{N}=16$ & $13 \%$ \\
Re-Operation & $\mathrm{N}=4$ & $3 \%$ \\
Elective & $\mathrm{N}=99$ & $80 \%$ \\
Euroscore I & $4.2 \pm 2.1$ & $1-15$ \\
Aortic ascendens & $4.2 \pm 0.6$ & $2.8-5.7$ \\
diameter $(\mathrm{cm})$ & & \\
\hline
\end{tabular}

primary indication for surgery was aortic valve disease in $n=73(63 \%)$ of patients. In $n=16(13 \%)$ of patients, an aortocoronary bypass presented an indication for sternotomy. In addition to the dilatation of the ascending aorta, primary cardiac surgery was indicated in all patients. Reduction ascending aortoplasty was performed as concomitant secondary surgery (Table 2).

\section{Surgical technique}

After complete longitudinal sternotomy in $63 \%$ of all patients (27\% underwent partial upper sternotomy), a cardiopulmonary bypass was established under moderate hypothermia $\left(34^{\circ} \mathrm{C}\right)$. The reduction ascending aortoplasty consisted of the direct resection of an oval section of the anterior wall of the ascending aorta. The expected reduction was calculated with the Roman formula [11] ( circumference $=2 \pi r \quad(r=$ radius, $\pi=3.14)$. The aortotomy was then adjusted in two layers with 4/0 Prolene ${ }^{\mathrm{TM}}$ (Ethicon Inc. USA) suture material. The aortoplasty was not additionally supported mechanically with prosthetic material. All associated indications for cardiac surgery were performed before the aortoplasty.

The patient follow-up data was initially collected by means of postal letters, telephone interviews and subsequent transthoracic echocardiography. If a CT of the chest had already been performed after hospitalization, echocardiography was not carried out and the data from the radiology test was used. The cumulative follow-up period consisted of 565 patient years and was concluded at $95 \%(\mathrm{~N}=119 / 124)$ for the endpoint "survival". An echocardiography was performed in 65 patients. The median follow-up period was 55 months and the mean follow-up time was $57 \pm 34$ months.

\section{Statistical analysis}

Continuous variables were specified as mean value \pm standard deviations. Nominal variables were described as numbers and percentages. Life tables were calculated with the Kaplan-Meier method. Significant predictors for a re-dilatation were first examined in a univariate analysis followed by a gradual logistic regression analysis.

\section{Table 2 Perioperative procedures}

\begin{tabular}{lll}
\hline Procedure & Number or mean \pm SD & Percent or range \\
\hline $\begin{array}{lll}\text { Concomittent aortic valve } \\
\text { replacement }\end{array}$ & 63 & $63 \%$ \\
Aortic valve reconstruction & 15 & $12 \%$ \\
Partial upper sternotomy & 33 & $27 \%$ \\
Comcomittent mitral & 11 & $9 \%$ \\
valve operation & & $13 \%$ \\
CABG & 16 & $1-6$ \\
Distal bypass anastomoses & $2,1 \pm 1,2$ & $0.6-5$ \\
Aortic wall resection (cm) & $1.6 \pm 0.9$ & \\
\hline
\end{tabular}




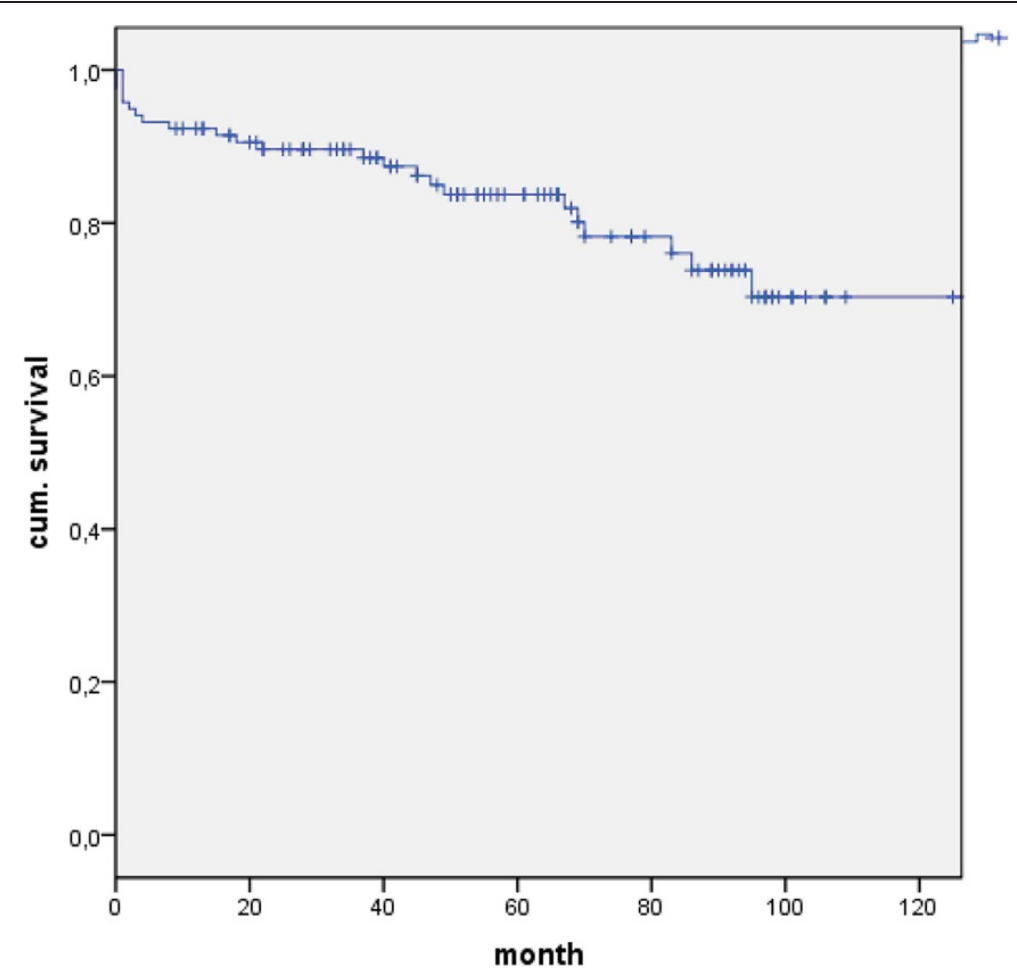

Figure 1 Kaplan Meier Curve for Survival after aortoplasty procedure.

Only variables which were significant in the univariate analysis were entered into the regression model. A p-value of less than 0.05 was considered to be statistically significant. Statistical analyses were carried out with the SPSS 21.0 software package (SPSS Inc., IBM, NY).

\section{Results}

Postoperative and perioperative mortality and morbidity Already during the primary hospitalization, 5 patients (4\%) died within the first 30 days after the procedure. The cause of death was low cardiac output syndrome $(n=3)$ as well as multiple organ failure $(n=2)$. Acute antegrade dissection was not reported.

\section{Long-term survival}

20 cases of late death occurred within the entire follow-up period. The patients' mean age of death was $72 \pm 11$ years. The exact causes of death could not be established. No autopsies were performed (Figure 1).

\section{Complications}

4 of 124 patients experienced increased secondary haemorrhaging after surgery which could not be managed despite conservative medicinal therapy. Re-thoracotomy provided evidence of the source of the haemorrhage at the aortoplasty suture line. The bleeding was stopped in all cases with surgical intervention (Table 3).

\section{Redilatation and repeat surgery}

With the technique applied for the reduction ascending aortoplasty, the aortic diameter $(3.6 \pm 0.6 \mathrm{~cm}$ range 2.3-4.9 cm) in the area of the ascending aorta was significantly reduced by $0.6 \mathrm{~cm}(\mathrm{P}=0.001)$ (Figure 2). Progression of the aortic dilatation occurred in 4 patients (Figure 3). With a baseline diameter of $3.3 \pm 0.5 \mathrm{~cm}$, the cross-section increased by an average of $0.9 \mathrm{~cm}$ in these patients $(4.2 \pm 0.7 \mathrm{~cm})$. In the remaining patients $(94 \%)$ the diameter was maintained with the reduction aortoplasty technique $(n=30)$ or decreased $(n=29)$. Repeat surgery with the indication of aortic revision were not reported during the follow-up period.

Predictors for redilatation: Only the preoperative diameter was identified as a significant predictor for redilatation.

Table 3 Follow up

\begin{tabular}{lll}
\hline Items & Number or mean \pm SD & Percent or range \\
\hline Age (years) & $72 \pm 11$ & $37-97$ \\
Lost to follow up & $5 / 124$ & $4 \%$ \\
Mortality rate & 20 & $21 \%$ \\
Atrial fibrillation & 27 & $27 \%$ \\
Aortic ascendens & $3.6 \pm 0.6$ & $2.3-4.9$ \\
diameter (cm) & & \\
Re-operation Aortic site & 4 & $4 \%$ \\
Warfarin therapy & 31 & $31 \%$ \\
NYHA III-IV & 8 & $8 \%$ \\
\hline
\end{tabular}




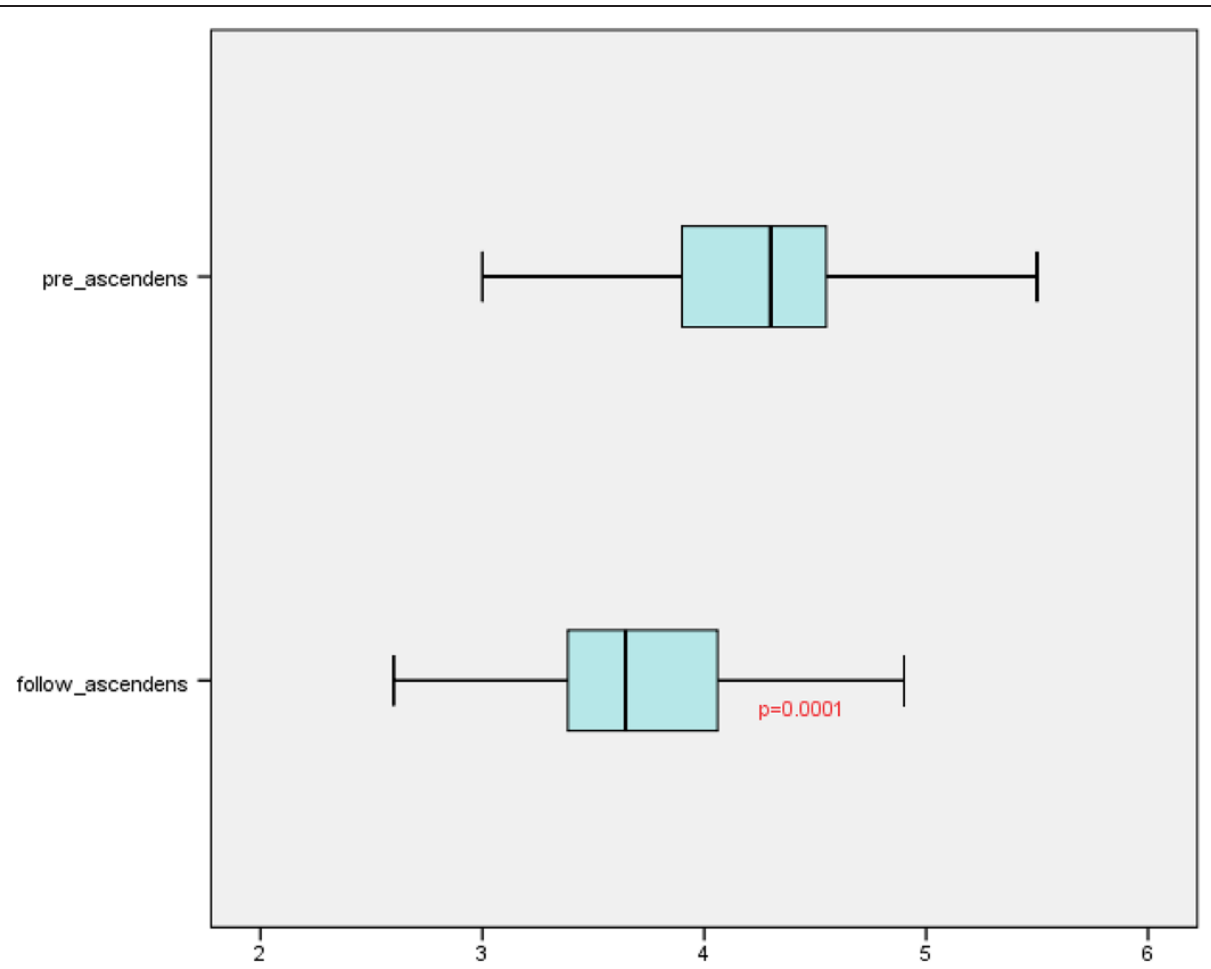

Figure 2 Boxplot of pre- and postoperative mean diameter of aortic roots after aortoplasty.

This applied only to patients with a smaller preoperative baseline diameter of $<40 \mathrm{~mm}$ where redilatation was not observed. Other pre- and intra-operative variables (e.g. surgeon) could not be evaluated as a predisposing factor for redilatation.

\section{Discussion}

The reduction ascending aortoplasty is a minimally invasive therapy option for dilatations of the ascending aorta and a viable alternative to radical aortic replacement. It is generally used for patients with borderline aortic dilatation or increased surgical risks [9]. Reduction aortoplasty can effectively decrease the aortic diameter or prevent further dilatation, shorten the aortic clamping time, and decrease the rate of mortality and morbidity $[12,13]$. Postoperative complications were mainly caused by the primary indication for surgery (aortic valve replacement or CABG). The good results of the perioperative

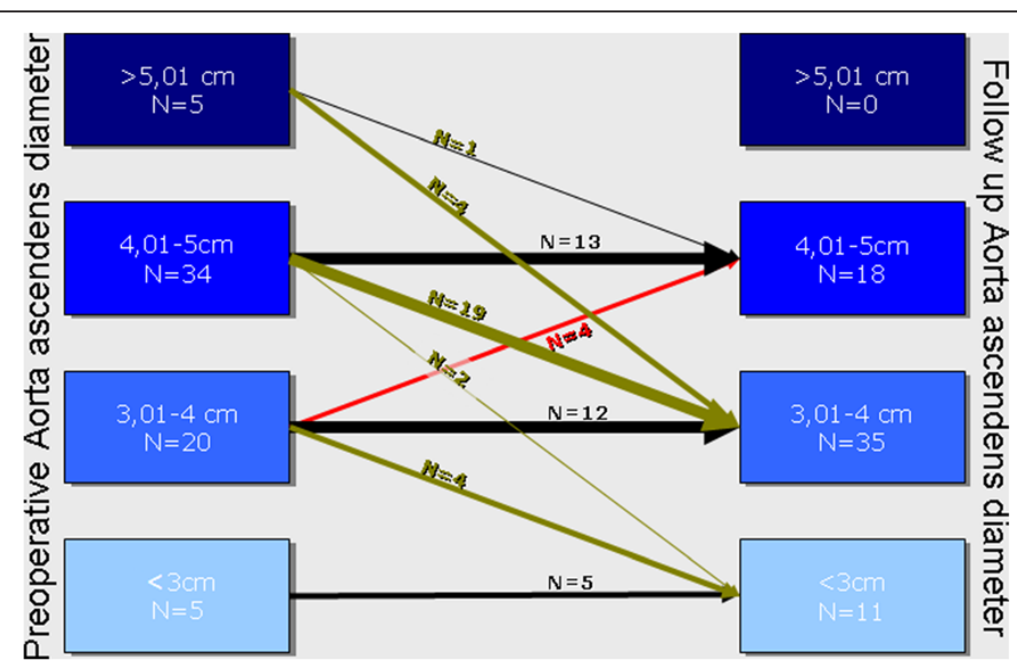

Figure 3 Changes of pre- and postoperative aortic diameters. 
RAA are in contrast to those of replacement of the ascending aorta. Replacement of the ascending aorta has a higher perioperative mortality and morbidity [4,5,14-16], but is justified by the number of different indications for surgery and patient characteristics [13]. Aortoplasty is contraindicated in patients requiring aortic replacement (type A aortic dissection, Marfan syndrome, cystic medial necrosis). Reduction ascending aortoplasty is generally performed in older patients with a high perioperative risk and in combination with another concomitant heart surgery. The greatest concerns with regard to aortoplasty as surgical treatment pertain to the rate of re-dilatations and mortality. During our follow-up study, 20 patients died. The causes are not known, but in view of concomitant combined cardiac procedures, connections to the underlying cardiac disease can be derived. The results are comparable with those of other studies $[2,8,9]$. Bauer et al. [13] reports a survival rate of $94 \%$ after 5 years and regards the aortoplasty-related mortality as very low. He believes that the reduction ascending aortoplasty has no effect on medium-term or long-term survival.

Literature research on the occurrence of re-dilatation after RAA shows contradictory results with rates of $0 \%$ to $25 \%[12,13,17]$. The lack of external support (wrapping) is made responsible for the differences, but a direct comparison between the studies is difficult due to the inhomogeneous groups. Arsan et al. [12] reports 35\% of patients with a combined aortic valve replacement as compared to Bauer et al, where $89 \%$ of patients received aortic valve replacement with RAA. In our study, the most relevant valvular heart disease was aortic valve replacement associated with relevant stenosis $(63 \%)$ while Bauer et al. [13] reported a percentage of $47 \%$. Muller et al. [18] also reports that all re-dilatations occurred in patients with Marfan syndrome, while other authors classified Marfan syndrome as an absolute contraindication for RAA [19-21]. We determined an absence of redilatation of $94 \%$ over a period of 10 years. Four patients had re-dilatation of the ascending aorta which did not require surgery. This result is similar to that of Bauer [13], Kamada [22] and Polvani [17]. There is a general consensus that RAA should not be performed on patients with an aortic aneurysm of more than $60 \mathrm{~mm}$ [2]. This is why this patient population is not represented in our population. Univariate and multivariate analyses confirm that the pre-operative diameter is the most important factor for RAA. However, these results mainly applied to a diameter of more than $55 \mathrm{~mm}$ [2]. However, our analysis also shows that at the other end of the extreme values, reduction ascending aortoplasty may fail, namely in those patients for whom dilatation of the aorta constitutes a borderline indication for surgery or a normal physiological width.

\section{Limitations}

The validity of this study is very limited. The following aspects should be critically noted: The study was only conducted in a selected subgroup of patients (maximum diameter of $57 \mathrm{~mm}$ ). There are no control groups where either no surgery was performed on the aorta or aortic replacement was carried out. Histology results on the morphology of the aortic wall were not collected. A 95\% follow-up rate with regard to the primary endpoint "death" is acceptable, but only $65 \%$ of patients could be motivated to undergo a follow-up echocardiography (redilatation as secondary endpoint).

\section{Conclusion}

For our patient population, reduction ascending aortoplasty is a safe and effective treatment option in patients with dilated ascending aorta $(<50 \mathrm{~mm})$ or significant contraindications for aortic replacement.

\section{Competing interests}

The authors declare that they have no competing interests.

\section{Authors' contributions}

AHK carried out the data recruitment, drafted the manuscript and performed the statistical analysis. EO carried out the follow up. AM performed the echo examinations. US, AZ and AM participated in the design of the study and. AM helped to draft the manuscript. All authors read and approved the final manuscript.

\section{Acknowledgement}

We would like to thank the team of study coordinators for their support on data recruitment, analysis and patient feedback.

\section{Received: 11 March 2014 Accepted: 29 June 2014}

Published: 5 July 2014

\section{References}

1. Ergin MA, Spielvogel D, Apaydin A, Lansman SL, McCullough JN, Galla JD, Griepp RB: Surgical treatment of the dilated ascending aorta: when and how? Ann Thorac Surg 1999, 67(6):1834-1839. discussion 1853-6.

2. Gill M, Dunning J: Is reduction aortoplasty (with or without external wrap) an acceptable alternative to replacement of the dilated ascending aorta? Interact Cardiovasc Thorac Surg 2009, 9(4):693-697.

3. De Paulis R, Cetrano E, Moscarelli M, Andò G, Bertoldo F, Scaffa R, Tomai F, Chiariello L: Effects of ascending aorta replacement on aortic root dilatation. Eur J Cardiothorac Surg 2005, 27(1):86-89.

4. Elefteriades JA: Natural history of thoracic aortic aneurysms: indications for surgery, and surgical versus nonsurgical risks. Ann Thorac Surg 2002, 74(Suppl):S1877-S1880.

5. Immer FF, Barmettler H, Berdat PA, Immer-Bansi AS, Englberger L, Krähenbühl ES, Carrel TP: Effects of deep hypothermic circulatory arrest on outcome after resection of ascending aortic aneurysm. Ann Thorac Surg 2002, 74(2):422-425.

6. Jault F, Nataf P, Rama A, Fontanel M, Vaissier E, Pavie A, Bors V, Cabrol C, Gandjbakhch I: Chronic disease of the ascending aorta. Surgical treatment and long-term results. J Thorac Cardiovasc Surg. 1994, 108(4):747-754.

7. Robicsek F, Cook JW, Reames MK Sr, Skipper ER: Size reduction ascending aortoplasty: is it dead or alive? J Thorac Cardiovasc Surg 2004, 128:562-570

8. Belov IV, Stepanenko AB, Gens AP, Savichev DD, Charchyan ER: Reduction aortoplasty for ascending aortic aneurysm: a 14-year experience. Asian Cardiovasc Thorac Ann 2009, 17(2):162-166.

9. Feindt $P$, Litmathe J, Börgens A, Boeken U, Kurt M, Gams E: Is size-reducing ascending aortoplasty with external reinforcement an option in modern aortic surgery? Eur J Cardiothorac Surg 2007, 31(4):614-617.

10. Robicsek F: A new method to treat fusiform aneurysm of the ascending aorta associated with aortic valve disease: an alternative to radical resection. Ann Thorac Surg 1982, 34:92-94. 
11. Roman MJ, Devereux RB, Kramer-Fox R, O'Loughlin J: Two-dimensional echocardiographic aortic root dimensions in normal children and adults. Am J Cardiol 1989, 64:507-512.

12. Arsan S, Akgun S, Kurtoglu N, Yildirim T, Tekinsoy B: Reduction aortoplasty and external wrapping for moderately sized tubular ascending aortic aneurysm with concomitant operations. Ann Thorac Surg 2004, 78:858-861.

13. Yun KL, Miller DC, Fann Jl, Mitchell RS, Robbins RC, Moore KA, Oyer PE, Stinson EB, Shumway NE, Reitz BA: Composite valve graft versus separate aortic valve and ascending aortic replacement: is there still a role for the separate procedure? Circulation 1997, 96(9 Suppl):II-368-II-375.

14. Beddermann C, Norman JC, Cooley DA: Combined replacement of the ascending aorta and the aortic valve in 42 consecutive patients: a comparison of composite graft techniques and conventional techniques over one year. Cardiovasc Dis 1980, 7:214-229.

15. Malashenkov Al, Rusanov NI, Muratov RM, Movsesian RA, Fursov BA, Bykova VA Tsoukerman Gl: Eight years clinical experience with the replacement of the ascending aorta using composite xenopericardial conduit. Eur I Cardiothorac Surg 2000, 18(2):168-173.

16. Bauer M, Pasic M, Schaffarzyk R, Siniawski H, Knollmann F, Meyer R, Hetzer R Reduction aortoplasty for dilatation of the ascending aorta in patients with bicuspid aortic valve. Ann Thorac Surg 2002, 73:720-723.

17. Mueller XM, Tevaearai HT, Genton CY, Hurni M, Ruchat P, Fischer AP, Stumpe F, von Segesser LK: Drawback of aortoplasty for aneurysm of the ascending aorta associated with aortic valve disease. Ann Thorac Surg 1997, 63:762-766.

18. Baumgartner F, Omari B, Pak S, Ginzton L, Shapiro S, Milliken J: Reduction aortoplasty for moderately sized ascending aneurysms. J Card Surg 1998, 13:129-132.

19. Barnett MG, Fiore AC, Vaca KJ, Milligan TW, Barner HB: Tailoring aortoplasty for repair of fusiform ascending aortic aneurysms. Ann Thorac Surg 1995, 59(2):497-51.

20. Carrel T, von Segesser L, Jenni R, Gallino A, Egloff L, Bauer E, Laske A, Turina M: Dealing with dilated ascending aorta during aortic valve replacement: advantages of conservative surgical approach. Eur I Cardiothorac Surg 1991, 5:137-143.

21. Kamada T, Imanaka K, Ohuchi H, Asano H, Tanabe H, Kato M, Ogiwara M, Yamabi H, Yokote Y, Kyo S: Mid-term results of aortoplasty for dilated ascending aorta associated with aortic valve disease. Ann Thorac Cardiovasc Surg 2003, 9:253-256.

22. Polvani G, Barili F, Dainese L, Topkara VK, Cheema FH, Penza E, Ferrarese S, Parolari A, Alamanni F, Biglioli P: Reduction ascending aortoplasty: midterm follow-up and predictors of redilatation. Ann Thorac Surg 2006, 82(2):586-591.

doi:10.1186/1749-8090-9-120

Cite this article as: Kiessling et al:: Midterm follow up in patients with reduction ascending aortoplasty. Journal of Cardiothoracic Surgery 2014 9:120.

\section{Submit your next manuscript to BioMed Central and take full advantage of:}

- Convenient online submission

- Thorough peer review

- No space constraints or color figure charges

- Immediate publication on acceptance

- Inclusion in PubMed, CAS, Scopus and Google Scholar

- Research which is freely available for redistribution 